\title{
Permanent pacemakers and the elderly: concerns, costs and benefits
}

There is much concern in the United Kingdom about the provision of pacing, both in terms of number of patients paced and modes of pacing used. Because fewer patients are paced than in most other European countries the United Kingdom has been dubbed "the poor man of Europe". ${ }^{1}$ The tendency for elderly patients to be given less complex pacing systems than younger patients ${ }^{2}$ has led to allegations of agism. ${ }^{3}$

\section{Pacing is underused}

In 1987 it was reported that the failure to pace appropriate patients was not due to lack of facilities, but rather to a lack of awareness on the part of doctors. ${ }^{4}$ A survey of doctors showed that neither resources nor difficulty in referring for pacing influenced the decision to recommend pacing. Rather, prior pacing experience was the main factor shown to be related to decision making. Cunningham et al showed that lack of pacing in the United Kingdom is not necessarily due to lack of resources. ${ }^{1}$ They attributed this lack to the small number of implanting centres. Others have also argued that devolution of pacing to district general hospitals will increase the availability of pacing and thus increase the number of patients paced towards the generally accepted target of 350 new implants per million per year. ${ }^{24-7}$ If a physician with an interest in pacing is appointed he may increase the referral rate elsewhere, or if he has the facilities he will pace more himself. ${ }^{8}$ In north east England the provision of pacing at some district general hospitals has led to a marked increase in pacing in those districts. ${ }^{9}$ Before this, however, the level of pacing in each district did not relate to distance from the regional centre, but rather to the interests and expertise of doctors in each district general hospital.

There is concern that small centres may have a higher complication rate and that they may restrict pacemaker implantation to VVI generators, which are technically easier to implant. ${ }^{5}$ None the less, cardiologists in district general hospitals have shown that they can provide an effective pacing service and that they can continue to update their experience in order to provide appropriate pacing for their patients. ${ }^{6910}$

\section{Pacing mode}

PRESCRIPTION OF PACEMAKERS

In 1991 the British Pacing and Electrophysiology Group published guidelines for the prescription of pacemakers, ${ }^{11}$ which generated controversy-not least among its authors. ${ }^{1213}$ There have been extensive published calculations relating to the costs of implementing these recommendations, ${ }^{214-16}$ with passionate arguments both for and against implementation. Despite concerns about costs, various centres changed their pacing practice after the guidelines were circulated, and the proportion of patients receiving dual chamber pacemakers has increased ${ }^{21617}$ by as much as $138 \%$ in certain groups.

\section{BENEFITS OF PHYSIOLOGICAL PACING}

Studies showing benefit of either dual chamber or rate responsive pacing have usually been restricted to small numbers of otherwise healthy patients in whom dual chamber pacemakers had already been implanted. The patients selected for study had thus already been chosen as likely to benefit from dual chamber pacing. These studies were conducted either acutely or over short periods. ${ }^{18-20}$ They showed that dual chamber pacing benefited these selected patients in terms of symptoms, cognitive functioning, exercise tolerance, and probably by the long term maintenance of sinus rhythm. These studies also suggested that patients prefer dual chamber pacing with preservation of atrioventricular synchrony to rate responsive pacing. The potential to increase heart rate may not be the only factor contributing to the improvement in quality of life.

\section{COST BENEFIT ANALYSIS}

Although there have been many comparisons of the cost of physiological pacing and VVI pacing, ${ }^{14-16}$ no information is readily available on cost benefit analysis. The costs of dual pacing over an estimated pacemaker and patient lifespan of 8 years are relatively modest. ${ }^{3}$

\section{DISADVANTAGES OF DUAL CHAMBER PACING}

It has been suggested that use of dual chamber pacing should be restricted because its increased complexity increases demands both on medical and technical time. ${ }^{21}$ Implantation is more difficult. Some centres have reported an increase in complications with DDD compared with VVI or single chamber pacing $(8 \cdot 7 \%$ v $2.9 \%$ for VVI pacing $)^{22}$ but others have reported low complication rates ( $5 \% v 4 \%$ for single chamber pacing). ${ }^{23}$ High throughput with experienced operators seems to reduce the complication rate. None the less, atrial leads become displaced more often than ventricular leads..$^{22}$

Atrial or dual chamber pacing is recommended for patients with sick sinus syndrome, who are liable to atrial fibrillation. ${ }^{11}$ Subsequent development of atrial fibrillation leads to loss of appropriate atrial sensing and pacing and dual chamber pacing may therefore not be possible in the long term in these patients. None the less, 90-92\% remained in DDD mode at one year and $78-83 \%$ at five years. ${ }^{1024}$ The commonest reason for loss of DDD pacing was the development atrial arrhythmias ${ }^{10} 24$; however, evidence suggests that in patients with sick sinus syndrome atrial pacing reduces the incidence of subsequent atrial fibrillation. ${ }^{26} 27$

Thus neither the increased complexity of dual chamber pacing nor concerns about the longevity of the mode seem to be valid reasons to deny it to patients. 


\section{PACING AND THE ELDERLY}

Because the paced population is elderly, most studies of pacing have been conducted in older patients. A few have been restricted to the very elderly. The same benefit in terms of symptoms and improved exercise ability (for example, time to ascend stairs) has been shown for dual chamber pacing in those over $75^{2829}$ as has been shown in younger patients. Again these were studies of patients who were already paced, and came from centres that implant DDD pacemakers in a few of their very elderly patients. ${ }^{216}$ Presumably therefore these patients had already been selected on clinical grounds as highly likely to benefit from DDD pacing.

Survival of the DDD mode may be less in the very elderly than in the overall paced population, but it was $78 \%$ at 30 months. $^{30}$

Petch has argued that because the elderly paced patient is likely to have other disease, the potential haemodynamic benefit of dual chamber pacing is of little consequence in day to day activities. ${ }^{21}$ This argument may be flawed and the converse may in fact be true. Those patients who have more symptoms and less cardiac reserve may benefit proportionately more than those who are otherwise healthy. The finding of improved cognitive functioning with DDD pacing ${ }^{20}$ may be of particular relevance in the elderly.

\section{Conclusions}

We need to increase the numbers of patients given appropriate pacing. This may be achieved by teaching general physicians and general practitioners about pacing, so that

1 Cunningham AD, Rickards AF, Nathan AW. Trends in pacemaker implantation: is the UK the "poor man of Europe"? [abstr] Br Heart $\mathcal{F}$ 1994;71 (suppl):P59.

2 Banning AP, McGurk LA, Avery P, Fraser AG, Buchalter $M$ Recommendations for pacing. BMF 1992;305:1431-2.

3 Payne GE, Skehan JD. Issues in cardiac pacing: can agism be justified? Br Heart f 1994;72:102-3.

4 Nathan AW, Paul VE, Judge K, Camm AJ. Survey of the attitudes of British physicians to pacing. Br Heart $\mathcal{f} 1994 ; 71: 96-101$.

5 Godden DJ, MacCulloch MS, Sandhu PS, Kerr F. Correcting a block? Successful experience of a small British pacing centre. Br Heart $\mathcal{f} 1987$ 58:495-8.

6 Doherty JG, Dawson F, Kerr F. Permanent pacemaker practice at a Scottish district general hospital between 1987 and 1993. Br Heart fournal 1995;73:475-8.

7 Pitcher D. Cardiac pacing: the service should be as local as the anaesthetic. Br Heart $\mathcal{F} 1995 ; 74: 7-8$.

8 Martin A, Nathan AW, Camm AJ. Cardiac pacing in an elderly population with a satellite clinic in a district general hospital. Age Ageing 1985;14:333-8.

9 Ibrahim B, Sanderson JE, Wright B, Palmer R. Dual chamber pacing: how many patients remain in DDD mode over the long term? Br Heart $\mathcal{F}$ 1995;74:76-9.

10 Bexton RS. 1994 Annual pacing report, Northern Region.

11 Report of a working party of the British Pacing and Electrophysiology Group. Recommendations for pacemaker prescription for symptomatic bradycardia. Br Heart f 1991;66:185-91.

12 Sutton R, Perrins J, Clarke $M$, Cobbe SM, Charles RG. Recommendations for pacing. $B M \mathcal{F}$ 1992;305:1432.

13 Ward DE, de Belder M, Jones S, Linker NJ, Camm AJ. Recommendations for pacing. BMf 1992;305:1432.

14 Ray SG, Griffith MJ, Jameson S, Bexton RS, Gold RG. Impact of the recommendations of the British Pacing and Electrophysiology Group on pacemaker prescription and the immediate cost of pacing in the Northern Region. Br Heart $\mathcal{f}$ 1992;68:531-4

15 de Belder MA, Linker NJ, Jones S, Camm AJ, Ward DE. Cost implications of the British Pacing and Electrophysiology Group's recommendations for pacing. $B M F$ 1992;305:861-5.

16 Channon KM, Cripps TR, Ormerod O. Recommendations for pacing. BMF 1992;305:1431.

17 Mounsey JP, Ray SG, Griffith MJ, Gold RG, Bexton RS. Impact of internal audit on pacemaker prescription and the immediate costs of pacin in the Northern Region: towards implementation of the recommendations of the British Pacing and Electrophysiology Group. Br Heart $\mathcal{F}$ 1994;71:395-8. they are more likely to refer appropriate patients. The establishment of more pacing centres in district general hospitals may increase the proportions paced-probably more by the appointment of physicians interested in cardiology and with experience in pacing than by bringing pacing closer to the patients. It is clear that experienced pacing physicians can provide effective pacing services in either district or central hospitals.

We do not need any more cost calculations. We know $\frac{T}{\mathbb{D}}$ that the hardware for dual chamber pacing is much more expensive than for VVI pacing. We need to find out who will benefit from more sophisticated pacing, and who will $\overrightarrow{\overline{\vec{n}}}$ not. Purchasers and politicians must decide if it is afford-무 able. The ideal mode of pacing that can be offered to a $\overline{\bar{\sigma}}$ patient is the most appropriate and the most cost effec- $\frac{\bar{\sigma}}{\frac{\sigma}{D}}$ tive for that particular patient. The cheapest option may not be the most cost effective. We already know that in small studies in selected patients dual chamber pacing is $\overrightarrow{0}$ better than ventricular pacing alone. Whether the results? of these studies can be extrapolated to the average paced $\vec{\omega}$ patient or to the paced population in general is not $\frac{?}{?}$ known. Expensive pacing modes should only be used if they are truly better than cheaper modes. To determine $\stackrel{N}{\perp}$ whether they are, we need to support the important randomised trials of pacing modes that are about to start in 0 the United Kingdom (Skehan JD, UKPACE, personal communication and Charles RG, personal communication), to await their results, and then to plan our pacing strategies on the basis of evidence rather than emotion.

JANET M McCOMB है

Freeman Hospital R S BEXTON

Newcastle upon Tyne, NE7 7DN

18 Kristianson B-E, Arnman K, Ryden L. The haemodynamic importance of $\stackrel{\mathbb{2}}{2}$ atrioventricular synchrony and rate interest at rest and during exercise. $\vec{F}$ Eur Heart $\mathcal{7 1 9 8 5 ; 6 : 7 7 3 - 8 .}$

19 Oldroyd KG, Rae AP, Carter R, et al. Double-blind crossover compar- 3 isons of the effects of dual chamber pacing (DDD) and ventricular rate $\bar{Z}$ adaptive (VVIR) pacing on neuroendocrine variables, exercise performance, and symptoms in complete heart block. Br Heart $f$ 1991; mance, and

20 Linde-Edelstam C, Nordlander R, Unden A-L, Orth-Gomer K, Ryden L. Quality of life in patients treated with atrioventricular synchronous pac- 岂 ing compared to rate modulated ventricular pacing: a long term double blind crossover study. PACE 1992;15(part I):1467-76.

21 Petch MC. Who needs dual chamber pacing? BMF 1993;307:215-6.

22 Chauhan A, Grace AA, Newall SA, Stone DL, Shapiro LM, Schofield 8 PM, Petch MC. Early complications after dual chamber versus single chamber pacemaker implantation. $P A C E$ 1994;17(part II): 2012-5.

23 Aggarwal RK, Connelly DT, Ray SG, Ball J, Charles RG. Early complications of permanent pacemaker implantation: no difference between dual $\frac{7}{2}$ and single chamber systems. Br Heart F 1995;73:571-5.

24 Gross JN, Moser S, Benedek ZM, Andrews C, Furman S. DDD pacing $N$ mode survival in patients with dual-chamber pacemaker. $f$ Am Coll o Cardiol 1992;19:1536-41.

25 Chamberlain-Webber R, Petersen MEV, Ingram A, Briers L, Sutton R. N Reasons for reprogramming dual chamber pacemakers to VVI mode: a $N$ retrospective review using a computer database. PACE 1994;17(part $\mathrm{\omega}$ I): $17-36$.

26 Hesselson AB, Parsonnet V, Bernstein AD, Bonavita GJ. Deleterious effects of long term single chamber ventricular pacing in patients with sick sinus syndrome: the hidden benefits of dual chamber pacing. $\mathcal{F} \mathrm{Am} \Phi$ Coll Cardiol 1992;19:1542-9.

27 Andersen HR, Thuesen L, Bagger JP, Vesterlund T, Bloch Thomsen PE. Prospective randomised trial of atrial versus ventricular pacing in sick $\frac{0}{0}$ sinus syndrome. Lancet 1994;344:1523-8.

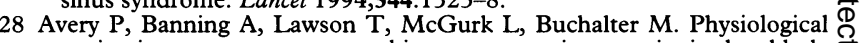
pacing improves symptoms and increases exercise capacity in the elderly $\frac{\mathbb{\Phi}}{\Phi}$ patient. Int $\mathcal{f}$ Cardiol 1994;46:129-33.

29 Channon KM, Hargreaves MR, Cripps TR, Gardner M, Ormerod OJM. O DDD vs VVI pacing in patients aged over 75 years with complete heart block: a double blind crossover comparison. $Q$ f Med 1994;87: 8 245-51.

30 Ray SG, Connelly DT, Hughes M, Bellamy CM, Charles RG. Stability of the DDD pacing mode in patients 80 years of age and older. $P A C E \underline{\underline{Q}}$ $1994 ; 17: 1218-21$ 